\title{
"Funky Days Are Back Again": Reading Seven- ties Nostalgia in Late-Nineties Rock Music
}

\author{
David Sigler
}

Observers of North American and British popular culture witnessed a strange and richly interesting phenomenon unfold between 1995 and 1999. During this period, the culture industry and its creative talent insistently described itself through Seventies imagery. The period oversaw the theatrical release of Jackie Brown, 54, and Velvet Goldmine as well as the television debut of That '70s Show, The State's "Barry and Levon," and the Travoltaesque Jack and Steve Butabi on Saturday Night Live. In response to our appetite for Seventies icons, formerly popular bands like the Sex Pistols, Steely Dan, Page and Plant, the Bee Gees, and the Guess Who scrambled to re-form after twenty-year hiatuses. Costumed hard-rockers Marilyn Manson and Rob Zombie, working in the tradition of Alice Cooper and KISS, became high school anthem-bearers. It seems that the late Nineties endured a flood of Seventies imagery across its popular media.

In an effort to reexamine the mechanics of popular nostalgia, this essay will engage only a small-but astonishing - corner of this phenomenon: the presentlooking Seventies nostalgia of the late Nineties in rock music. Although nostalgia had always been a valuable property for the culture industry, a distinct strain emerged during the late Nineties: whereas traditional forms of commercial nostalgia have re-branded "pastness" and descriptions of previous times as stable entities to be sold to anxious and possibly aging consumers, the new "present-looking" nostalgia did not seek to repackage the Seventies as such. Instead, it depicted the late

David Sigler is a doctoral candidate in English at the University of Virginia. His dissertation, "Romantic Sexuation," offers a psychoanalytic account of gendering in Romantic-era British prose. 
Nineties through imagery closely associated with the Seventies. In its descriptions of contemporary conditions, the present-looking Seventies nostalgia should be distinguished from more traditional forms of rock music nostalgia that circulated contemporaneously (for example, Smashing Pumpkins" “1979” or Everclear's “A.M. Radio"). Present-looking Seventies nostalgia represented a specific and sometimes engaging strain of rock-n-roll that still tends to confound standard strategies of theorizing nostalgia in popular culture. Because it focused on the return of the Seventies instead of the Seventies as such, a convincing reading of this presentlooking nostalgia would demand new interpretive strategies that emphasize the poetics of redoubling and return as much of those of longing and restoration.

This essay will interrogate current models for understanding nostalgia, showing how even our best nostalgia theorists tend to efface questions of desire by treating nostalgic texts primarily as commodities and as symptoms of "the times." Resisting the reductiveness of such readings, this essay seeks to reintroduce desire into the analysis of present-looking Seventies nostalgia in many of its lateNineties incarnations as musical commodity. I have chosen five examples of the subgenre (Wilco's "I Got You [At the End of the Century]," U2's "Discotheque," Neil Young's "Downtown," The Tragically Hip's "Fireworks," Cornershop's "Funky Days Are Back Again," and Beck's Midnite Vultures) ${ }^{1}$ to illustrate that, despite the diversity of their longings and the fact that each text forges unique relationships to the Seventies, nostalgia, and the late Nineties, present-looking Seventies nostalgia is consistently formulated in relation to desire. I am not so much interested in the ways that these songs recall specific sounds or production values of the Seventies; rather, I hope to show how these songs share the unusual distinction of using Seventies imagery to update their sound for a reinterpretation of the late Nineties. The music discussed in this paper proves supple enough to serve diverse and often contradictory purposes, forging an ambivalent relationship to the return of the Seventies in the late Nineties. It is because of the centrality of ambivalence in each of these cases that these songs so tenaciously resist the rigid categorizations and reductive reading strategies that so often characterize even the most sophisticated nostalgia theory. The present-looking impulse demands a different model for understanding its nostalgia: it requires a listening strategy grounded in ambivalence and desire, one that can recognize the uncanniness of a return of a lost object and still acknowledge that these texts are capitalist commodities.

Significantly, all of the artists represented in this study are male. While this might be a result of the narrow generic scope of this study, ${ }^{2}$ it might also suggest that nostalgia for the Seventies in the late Nineties was especially the preoccupation of male artists. Janice Doane and Devon Hodges have argued that nostalgia is a predominantly male construct representing the pull of conservatism, an intrinsically "antifeminist impulse" (xiii). Barbara Creed has similarly linked nostalgia to misogyny in her discussion of film. Although I would not agree that nostalgia is in itself patriarchal, the masculine flavor of present-looking Seventies nostalgia should make us wonder if the songs in this study exert a force of exclusion that quietly works to perpetuate the inequalities that have always structured the rock-n-roll format. ${ }^{3}$ Of course, rock music was itself an object of nostalgia by the late Nineties: 
Lenny Kravitz had long since proclaimed the death of the genre, and the future-or at least the present-appeared to be in electronic and rave culture, hip-hop, artful experimentation à la $O K$ Computer, and the anti-experimentation of the slick pop boy-and-girl-band formats.

Even beyond problems of genre and gender, we should wonder why the category of present-looking Seventies nostalgia suddenly asserted itself in the midNineties and flourished both commercially and aesthetically for the duration of the decade. Whereas it would be easy to attribute the phenomenon to the acceleration of economic and cultural globalization, the pressures of a music industry then enduring major-label mergers to the detriment of many album-oriented rock artists, the radically atemporal spaces now available on the Internet, the emergence of peer-to-peer file-sharing networks such as Napster, the technological optimism of the NASDAQ boom, the ahistorical pastiche-effect demanded by postmodernity, or the aesthetic "vacuum" left by the 1994 suicide of Kurt Cobain, I fear that a series of these or other base-superstructure arguments would prove reductive in these and many other cases. In the hopes of generating a theory that can accommodate these rich cultural texts, one that can account for both desire and ambivalence, I prefer Stephen Paul Miller's strategy of "uncanny criticism," which offers "readings that become possible by noting relationships between phenomena" instead of focusing on providing a thorough explanation for them (35). In my view, presentlooking nostalgia necessarily participates in the uncanny, as the uncanny by definition always "leads us back to what is known of old and long familiar" (Freud 220). Freud, in famously presenting the uncanny in ambivalent relation to the heimlich (homely) and heimisch (native), treads theoretical ground common with the original medical discourse of nostalgia. Given the shared themes of homesickness, nativity, homeliness, and the return, we might risk the claim that nostalgia is necessarily uncanny, just as the uncanny is necessarily rooted in desire. Nor should a commitment to the study of desire and the uncanny preclude us from attending to the capitalist logic of the culture industry. Indeed, students of the uncanny - and here we would have to include gothicists, horror film scholars, and psychoanalystshave often been among the first to lend careful attention to processes of commodification and the marketing of specific genres. I am simply arguing that we should resist attempts to resolve or explain away the ambivalence of certain nostalgic commodities. Rather, we should learn to let the desire of the commodity speak and to recognize its uncanny effects.

The theorization of nostalgia has a rich academic history, one that this study hopes to participate in but not recount at length. ${ }^{4}$ In recent years, post-Fifties nostalgia has been a topic of much academic discussion. Nora Sayre shows that the Sixties proved nostalgic for a Romantic pre-industrial simplicity. Peter Biskind casts the Seventies as a "golden age" of film that reinvented itself through the noir films of the Thirties and Forties. Fredric Jameson explores how the conservative Eighties yearned for the seemingly stable family unit of the Fifties. Paul Grainge describes how the Nineties re-branded black-and-white images as "classic" to fuel a spree of global consumerism. Nostalgia is most frequently studied as a form of commodity. For instance, Michael Kammen decries the commodification of nostal- 
gia in the Seventies through the Nineties, claiming that nostalgia functions to allow the postmodern subject "history without guilt" (157); Grainge, echoing these concerns, suggests that nostalgia first became thoroughly commodified in the Seventies (20).

Among these, few nostalgia theorists can resist the easy coinages that express the now-clichéd paradoxes of nostalgia: phrases such as "the cutting edge of retro" (Rachman 52), "an 'absent' present" (Ritivoi 35), and "nostalgia isn't what it used to be" (invoked in turn by Signoret, Davis, and Grainge) abound. The consistent reliance on irony and paradox to explain the workings of nostalgia in popular culture suggests that nostalgia is a self-contradictory impulse with unclear boundaries and effects; nevertheless, the reassurance provided by the succinctly-phrased paradox makes nostalgia seem clever instead of uncanny. For the same reasons, theorists tend to divide cultural nostalgia into tidy and distinguishable categories, such as Fred Davis's “orders of nostalgia," Jameson's "mood" versus "mode" distinction, and Svetlana Boym's "reflective" versus "restorative" formulation —all of which break down immediately in the face of the music featured below. As if recalling its point of origin, nostalgia has also tended to be discussed in recent years through medical metaphors. Boym typifies this tendency in describing nostalgia as "the incurable modern condition" (xiv); more commonly, the metaphor serves to fashion nostalgia as a symptom of economic globalization.

Of the many versions of the claim that nostalgia participates in and obscures the logic of global capitalism, Jameson's remains the most prominent. Decrying the inauthenticity of nostalgia, Jameson describes the nostalgic mode as a series of pastiches that typify postmodernism's peculiar lack of historical understanding. In Jameson's view, as the "incompatibility of a postmodernist "nostalgia' art language with genuine historicity becomes dramatically apparent" (Postmodernism 19), nostalgia becomes an "embarrassing ... cultural fantasy" (170), an impediment to "real" knowledge. Elsewhere, Jameson describes nostalgia as "costume-party self-deception" ("Nostalgia" 536), representative of the dreaded "Nietzschean position" and therefore "a lie" (525). Boym takes this argument in another direction, suggesting that Nineties nostalgia resists the logic of late capital and compensates for it: if "American popular culture has become a common coin for the new globalization" (39) then nostalgia counteracts this in that it "demands a different currency" (xvii).

Although Boym's explanation does not clarify the issue-why would nostalgia demand a different currency? What happens when popular culture is itself both nostalgic and global? - it does point to a tension implicit in the songs that will be the objects of this study. In their mission to make aesthetically interesting rock and to sell albums, these songs all participate in and themselves constitute the very postmodern nostalgia that they seem to be trying to resist. Such contradictions remind us that nostalgia and commodity were closely interrelated in the Nineties. Nevertheless, this series of medical/economic metaphors tends to distract the listener from examining the nostalgic text as such. When we invoke the readymade imagery of global economics and disease, we tend to read nostalgic cultural texts merely as symptoms of admittedly more important problems. The problem with even the most sophisticated recent nostalgia theory as it describes popular culture 
is that nostalgic cultural productions stop generating their own internal meanings when we use them only as signposts to illustrate more distant and abstract phenomena.

Although the songs considered here are all commodities produced, packaged, and sold by the culture industry to generate enormous profits, and although all of the songwriters involved here enthusiastically participate in the marketing and selling of their creative output, it nevertheless dangerously oversimplifies these musical texts to describe them as "mere" commodities. Such, however, has been the prevalent explanation since Adorno and Horkheimer first tuned their attention to the culture industry. For Rachman, Seventies nostalgia in the Nineties amounts to a marketing scheme to "package the past for contemporary consumption" (44). Miller reads the Seventies nostalgia films of the Nineties as a mere "prepackaged archeological dig" (33). Boym echoes this, describing nostalgic popular texts of the Nineties as "a quick fix and sugar-coated palliatives" that reflect "a fear of . . noncommodified time" (xvii). While the songs considered here undoubtedly participate in the general Nineties commodification of nostalgia, I will nevertheless insist that to accept commodification as a sufficient explanation of their relationship to Seventies nostalgia in the late Nineties would prevent us from examining their uncanny relationship to the culture of commodified nostalgia that they are desiring, describing, enacting, and selling.

I undertake this study partly to recomplicate the relationship of the musical commodity to nostalgia, finding a way to account for the commodity's disquiet in the capitalist forces it participates in. It does us no good to disparage forms of nostalgia as "inauthentic," as James Hart has effectively done in saying that nostalgia "does not have the original givenness of the actually really existing" (406), and as Boym has in arguing that "the danger of nostalgia is that it tends to confuse the actual home and the imaginary one" (xvi). I would instead suggest that popular culture in the late Nineties was always already saturated with and structured through nostalgia, radically confusing the (ultimately false) distinction between "actual" and "imaginary" homes. In these quotations, Hart and Boym alike raise the lost object of nostalgia to the level of the Thing, fundamentally misconstruing the mechanics of the drive. Nostalgia is not a yearning for the "actually really existing" or the "actual home": nostalgia seeks a partial object that will inevitably fail to satisfy any drive. Hart and Boym are not alone in this misunderstanding: nostalgia theory in general has tended to critique nostalgia as misguided when it does not attain the Thing-in-itself. Little wonder, then, that such criticism has had trouble accounting for the enjoyment that nostalgia produces in popular culture. By focusing only on nostalgia as a form of insincerity, these critics have dissuaded us from pursuing questions about enjoyment and the path of desire.

To her credit, Boym herself points us in a more promising direction. Her statement that "the alluring object of nostalgia is notoriously elusive" (xiv) recalls Jacques Lacan's formulation of the excessive and unnamable objet a. Lacan can hardly be claimed as a nostalgia theorist, even if he ranks among the most important theorists of the lost object. But while discussing the differences between ancient and modern love in Seminar VII, Lacan remarks that preferring the ancients to the moderns 
qualifies as a form of nostalgia, one that emerges as "the result of a certain loss, a cultural loss, of the object" (99). In Lacan's view, "nostalgia . . means no more, like every dream of a Golden Age or El Dorado, than that we are engaged in posing questions at the level of the instinct because we do not yet know what to do as far as the object is concerned" (99). Lacan here affords us a fruitful departure for our examination of present-looking Seventies nostalgia. We will find in the discussion of the songs below that nostalgia appears at the level of the instinct (or drive) because the Seventies as a lost object returns only ambivalently. Without closer investigation from the level of the drive, we probably won't "know what to do" when considering the return of the Seventies in late-Nineties rock music.

Dramatizing a standard explanation for late-nineties retro, Wilco's song "I Got You (at the End of the Century)" from 1996's Being There seems to offer nostalgia as the antidote for fin-de-siècle anxiety. Drawing its chord changes and hopeful melody from Seventies musical influences as far-flung as John Lennon, Alice Cooper, and Big Star and its millennial perspective from the Ramones, frontperson Jeff Tweedy declares that "It's the end of the century / And I can't think of anything / But you." The twist here is that "you" seems to draw her reassuring power directly from the Seventies. Tweedy explains his reliance on "you" in relation to a distanced Seventies experience: "All the way back in the Seventies / You were my little T.V. queen / Tarzan and your friend Janine." In this sense, it would seem that Tweedy can only reassure himself about the advent of Y $2 \mathrm{~K}$ with recourse to "you" as a remnant of the Seventies. Tweedy's late-Nineties appeal to "you," or rather something in "you" more than "you," makes this song an excellent example of presentlooking Seventies nostalgia: for Wilco, the century's impending end is designated as the time of reminiscence. All of the "action" takes place in the Seventies as a strategy for addressing specifically late-Nineties anxiety.

In this context, the word "still" gains special significance for the lines "I got you and I still believe / That you are all I will ever need." Suggesting the increasing complicatedness of the late Nineties (as in the fact that his reliance on "you" seems to belong to remote Seventies experiences), Tweedy presents the Seventies as a simpler time when recourse to "you" might have been reasonable. He seems defiant in insisting that the thin ideal of "you" still holds value for him at "the end of the century." The interaction of the words "still" and "ever" present a paradox, implying that recourse to nostalgia may ultimately be nothing but self-deception: if Tweedy were secure in believing that "you are all I will ever need," he wouldn't use the word "still" to describe his belief. Moreover, Tweedy here seems to acknowledge the inappropriateness of his thoughts (a sense of surprise and disappointment pervades his claim that "It's the end of the century / And I can't think of anything / But you"), but he nevertheless takes comfort in this fixation. The only information we get about "you" is her association with Tweedy in the Seventies and "your" friendship with the Bowiesque "Janine." We can only assume that this single trait of "yours," namely being associated with the Seventies in some unspecific way, is the reason why Tweedy turns to "you" at the end of the century. One interpretation, then, could understand Tweedy's "you" as a direct personification of the Seventies and take the Seventies itself to be the coveted lost object of 
Tweedy's nostalgia. Understanding their relationship thus, we could say that "you" simply functions as a lost object, remaining inaccessible ("All the way back") but "still" functioning as a desired object against the perceived chaos of a century's end. This reading would be consistent with Boym's description of nostalgia as "an emotional antidote to politics" (58). Such logic would understand "I've Got You" as a reassuring distraction from the confusion of late-Nineties existence, as a stabilizer and rudder for navigating postmodernity intact.

A problem emerges for this interpretation, however, when we see that anxiety, millennial or otherwise, is by definition alien to the logic of nostalgia. As Joan Copjec has reminded us, anxiety "is that which nothing precedes" and therefore it always "registers the non sequitur" (118). According to Copjec, anxiety "signals a lack of a lack," a problem she also formulates as "overproximity to this object $a$ " (119). Nostalgia, of course, depends on both a lack and a precedent, making it entirely incommensurate with anxiety. But Wilco's song undeniably expresses both anxiety and nostalgia: how could Wilco yearn for a Seventies past, we wonder, when the late Nineties represent precisely that which nothing precedes? Only when we begin to understand Tweedy's relation with "you" as uncanny does this seeming contradiction disappear. The late Nineties indeed can be "that which nothing precedes" insofar as the Seventies and Nineties coexist in uncanny relation to each other in the present. Time has been flattened out in Wilco's song, not by any postmodern pastiche-effect of the nostalgic mode but rather by the uncanny return of the Seventies in the Nineties. Copjec clarifies the issue by introducing the element of the uncanny into her account of anxiety: "[T]he special feeling of uncanniness is a feeling of anxiety that befalls us whenever we too closely approach the extimate object in ourselves" (129). Copjec has helped us unravel the path of Tweedy's desire: the "you" of the song can only be understood as Tweedy's double. This would indeed explain how "you" could satisfy Tweedy at the level of the Real ("you are all I will ever need"), and yet be associated with a remote Seventies experience at the level of the Symbolic. In Copjec's terms, "this double is endowed with the object that we sacrificed in order to become a subject" (129). Tweedy, we can deduce, has sacrificed the "you" of the Seventies-now understood as a part of himself outside of himself, his extimate object - to produce what has become his nostalgic end-of-the-century subjectivity. His longing for the "you" whose single trait is rooted in the Seventies marks the uncanny return of the sacrificed extimate "you" at the end of the century. Wilco thus confirms Lacan's claim that nostalgia can be best understood at the level of the instinct.

$\mathrm{U} 2$, more distant from the objet $a$ and consequently less anxious than Wilco, invoke present-looking Seventies nostalgia to explore and expand the boundaries of the ego. As the first single and lead track on Pop (1997), their song "Discotheque" climbed to \#1 in thirteen countries, becoming one of the Irish band's biggest career hits. U2 offers "Discotheque" as a way to imagine Nineties electronic music filtered through the sound of a guitar-rock band and recast in terms of the Seventies dance club. Combining the heavily distorted guitar tone of the Edge with a sample of Freeform's 1996 electronica experiment "Fane," U2 seems to be suggesting the present of the discotheque as much as its past, qualifying this song 
as another example of present-looking Seventies nostalgia. Whereas Wilco describes as uncanny "your" proximity to the objet $a$, U2 recognizes "your" distance from the objet $a$ in the very first line of the song ("You can reach, but you can't grab it"). Offering lyrics in the present tense and second person, the band imagines the discotheque as a site of both self-transformation and membership in an illicit underground subculture: "You know you're chewing bubblegum, / You know what that is but you still want some." Punning "Let go!" with "Let's go," U2 imagines the discotheque as the radical projection of interiority, a dynamic made especially clear in the song's bridge: "You know that you're somewhere else instead / You want to be the song / The song that you hear in your head." By strangely locating the song "in your head" (although it quite obviously fills the entire club) and suggesting that "you" might actually come to be the song, Bono implies that "you" have expanded your ego to include the sum total of the drives that are occasioned and mediated by the Seventies discotheque, to paraphrase Maria Torok (Torok 108). The guitar effects respond to this expansion. Shifting from one of the most flamboyantly overdistorted and thin guitar sounds in recent memory to a pristine reverb-and-delay tone on the arpeggiated bridge section, the guitar tone suggests the process of introjection that the discotheque supports and sustains. The guitar track here combines reverb and echo effects (as if our ego suddenly discovered that it inhabited a much larger but still enclosed unconscious) with delay (the effect of nostalgia and the uncanny return). Possibly because of the sudden removal of repression, we remain undeterred when Bono reminds us of the limits of our introjection: "You know there's something more / but tonight, tonight, tonight / Boom Cha!" Here and throughout the song, Bono speaks in the voice of the superego, effectively issuing the obscene injunction to "Enjoy!" even while acknowledging the insatiability of the drive with the phrase "You just can't get enough."

The video for "Discotheque," among the band's most memorable, is set inside a giant mirrorball. Inside, we find the band dressed as the Village People but keeping "straight" faces, bringing Seventies versions of quasi-closeted camp culture into the Nineties through the Edge's mirrorball-pattered Les Paul and Bono's inimitable falsetto. For U2 as well as late-Nineties popular culture more generally, the mirrorball came to suggest the hedonism and self-transformations of the Seventies. ${ }^{5}$ It offered U2 an enduring symbol of the Seventies, a concrete and glittery image simultaneously inward-looking and social. The mirrorball, like the song "Discotheque" which appropriates it, suggests the social consequences of personal reinvention, offering itself as a symbol for unity (its globular shape bringing the world together through dance) and fragmentation (casting beams of light around the room, the mirrorball symbolizes our transformed, multiple, and extroverted selves as we discover them under its sway). U2's nostalgic redeployment of the mirrorball, then, confirms Davis's claim that "nostalgia is ... one of the more readily available psychological lenses ... we employ in the never ending work of constructing, maintaining, and reconstruing our identities" (31). The point here is not that U2 discovered a new metaphor for introjection-indeed, the link between the expansion of the ego and the mirrorball seemed so clichéd by the late Nineties that we 
might say that U2 was the last band anywhere to articulate it-but rather that U2 exploited a dead metaphor of the Seventies as an effective means of accounting for their uneasy position within a globalizing culture industry.

Grotesquely literalizing a lyric from Pop's "If You Wear that Velvet Dress" ("Tonight the moon is a mirrorball / Light flickers from across the hall"), U2 consistently performed "Discotheque" on their ensuing PopMart tour by emerging from a giant lemon-shaped mirrorball. Even beyond its value in representing the transformed neo-Seventies self, this now-infamous PopMart mirrorball became an apt symbol of the band's recent musical adventures. Encapsulating the pre-oedipal pleas of "Mofo" in its womb-function at the level of the Imaginary, the avant-garde German-style club music of "Lemon" in its shape, the "Discotheque" video in its setting, the Seventies discotheque in its mirrorball surface, Warhol in its absurdity, and disco culture in its fruitiness and "unnaturalness," U2 presented its fans with the ultimate signifier of present-looking Seventies nostalgia. The PopMart tour cleverly flaunted U2's uneasy relationship with rock-n-roll nostalgia, repackaging Seventies imagery and values as the paradoxical culmination of the band's fiveyear project of present-looking and accessible experimentalism. Fans at PopMart found a band long admired (and mocked) for its sincerity embracing the campy spectacle of the Framptonic stadium tour. Onstage we find the band dwarfed by giant arches and video screens, dressed with all the absurdity of Seventies fashion: Bono's leather, the Edge's faux-cowboy hats, Adam Clayton's orange jumpsuits, Larry Mullen's clean-cut "macho man" minimalism. The tour critiqued corporate rock from within, often drawing on Seventies imagery (including a session of Neil Diamond karaoke and the swanky sleaze of "The Playboy Mansion") to send up the crass commercialism of the Seventies-style mega-stadium tour, themselves generating huge turnstile and merchandise revenues all the while.

To offer a point of comparison for the nostalgic styles invoked by U2's discotheque-and-mirrorball imagery, let's shift our attention now to Neil Young's "Downtown," the radio single from the Winnipeg songwriter's 1995 collaboration with Pearl Jam entitled Mirrorball. The Mirrorball project can be read both as Neil Young continuing to update his sound after his renewed Nineties popularity following the success of Freedom and Harvest Moon, and as Pearl Jam latching on to Young's credibility as they begin to stake their own claim as veteran rockers. To the benefit of both himself and Pearl Jam, Young emerged from the Mirrorball sessions with a new nickname, "the Godfather of Grunge," which in its genealogical implications and allusion to Seventies film presents the Mirrorball album as both a continuation and newest instantiation of the rugged guitar-rock aesthetic that Young perfected in the early Seventies. The album can be understood as an intergenerational collaboration of musicians that-especially when imagined as part of a wider "grunge" movement, which "can be said to layer and to codify stereotypical beatnik, hippie, and punk styles" (Miller 33)-promises to position the history of rock music outside of linear time.

As part of this investiture in the rock and roll tradition, "Downtown" collapses the Sixties and Seventies into the present tense and spatial-geographical terms. Imagining rock history as a happening nightclub somewhere between the Rock and 
Roll Hall of Fame and Studio 54, Young here invites us "to a place called downtown / Where the hippies all go." Breaking down Jameson's distinction between the "nostalgic mood" the "nostalgic mode," Young sincerely yearns for his Seventies heyday through an antihistorical pastiche of Sixties/Seventies rock imagery. Grainge, following Jameson in describing the nostalgic mood as an insincere reaction-formation designed to falsely reassure consumers, might understand a text like Young's as a "cultural response to forms of discontinuity, claiming a vision of stability and authenticity in some conceptual 'golden age" " $(21){ }^{6}$ I would further complicate the interpretation of ahistoricity in "Downtown" by understanding its temporal conflation not as a symptom of a generalized postmodern failure to understand the dialectic of history, but as part of a self-described "psychedelic dream." Boym has rightly argued that "nostalgia speaks in riddles and puzzles" (xvii), and "Downtown" is no exception: Young offers the listener a text that must be read associatively through the channels of desire if its wishes are to be understood.

Like U2's falsetto-affected and village-peopled "Discotheque," Young's fantasy nightclub offers us a world of sound and vision replete with homoerotic suggestion. In its "mirrorball twirlin'," the allure of "the back room," and the risk of getting "sucked in," Young's fantasy recalls "the sense of helplessness experienced in some dream-states" that Freud allows as uncanny (237). Hippie culture had largely seen itself in masculinist-heterosexual terms. As Robert McRuer has argued, Sixties and Seventies counterculture "had a complicated and often problematic relationship to race, gender, and sexuality ... . [T] he counterculture was predominantly white and male ... not only predominantly male but openly sexist" (217). But Young's "Downtown," far from being "openly sexist," offers itself as a site where one can simultaneously exercise the gaze and be evaluated under it, allowing one to more safely invite and stave off potential sexual partners of any gender or sexual orientation: "Yeah, the hippies all go there / Because they wanna be seen / It's like a room full of pictures." Young's simile here recalls Lacan's description of the line and light in Seminar XI: "The picture, certainly, is in my eye. But I am not in the picture" (96). Young seeks a space where his vision can regard itself, can function as its own double. Providing himself with his own extimate ego ideal, Young stands in the downtown club at the place "from which the subject will see himself, as one says, as others see him" (Lacan, Seminar XI 268).

Hence the double function of Young's downtown rock club: Young can cast himself as part of the audience even though the song implicitly reminds the listener that he and Pearl Jam belong in the company of the immortal(ized) club performers. The nostalgic mood in this imaginary rock club is established by the convergence and literal immortality of its performers: "Jimi's playing in the back room, Led Zeppelin onstage / There's a mirrorball twirlin', and a note from Page." Invoking the undead Hendrix and John Bonham, and giving us unfettered access to the "back room" and its correspondences, Young recounts a dream of "Downtown" as an accessible space for love, creativity, freedom, and community. Redoubling the effect of the gaze by placing legendary musicians in the place of the spectators, in offering an uncanny space that contains disruptions in identity and finds ways to render available counterculturally prohibited erotic object-choices, and not least in 
its roll-call of famous rock musicians, Young's downtown club emerges as a sort of "Max's Kansas City 1976" for 1995.

Young, of course, has invited us downtown before, most directly on 1975's "Come on Baby Let's Go Downtown." The song, initially presented by Young on his alcoholic-mourning-and-melancholia cycle Tonight's the Night, acknowledged the death of Crazy Horse guitarist Danny Whitten. The act of going downtown was already atemporal in its 1975 incarnation: the song, featuring Whitten's vocals, was presented alongside material Young had recorded after Whitten's death and of fered as part of the immediate present-hence the album title-in tribute. Mirrorball's version no longer mourns Whitten as a lost object. Young even goes so far as to recommend perseverance in the work of mourning (by way of a kitschified allusion to Greek mythology) by having the club's resident hippies "do the Limbo." But with Whitten already behind him, Young reiterates the invitation to "go downtown" from 1975 (an invitation that was itself presented nostalgically) so as to reposition himself and the listener in the midst of his mid-Seventies prime. In both its Mirrorball and Tonight's the Night incarnations, Young imagines "Downtown" as an archive of the authentic rock-n-roll soul. And "being" (as opposed to merely "having") authentic rock-n-roll, in Young's case, means the elision of the Eighties, a move that the return of the downtown fantasy guarantees. In establishing the imaginary club - and therefore Seventies rock — as a site of "being," Young encases Mirrorball within the imagery of these decades and elides his own dubious experiments of the Eighties. In a sense, "Downtown" allows Young to efface his inconsistent and regrettable political commitments in the ahistorical vision of a throwback nightclub, transforming his sound from "retro" into "classic" by mapping himself directly onto the Seventies without acknowledging any chronological rupture.

This strategy is literalized by the graphic design of the compact disc itself, offering the initials "NY" in a retro-Seventies font inscribed across the shiny surface of the disc-disguised-as-mirrorball, a disc that proclaims itself simply as Mirrorball. Thus it becomes possible for a compact disc to function as a fabricated Seventies artifact marked with Young's own initials, the shiny and round disc proving to be a well-suited surface upon which to fashion the likeness of a mirrorball. It also implies that the Seventies mirrorball has bestowed this Nineties rock project with its legendary authority.

Young, in illustrating the tension between affirming one's individual relevance and erasing it, seems to involve himself in the characteristically postmodern tension between irony and nostalgia as Linda Hutcheon has described it. But Hutcheon makes a strange claim about postmodern aesthetics when she claims that "nostalgia no longer has to rely on individual memory or desire: it can be fed forever by quick access to an infinitely recyclable past" (196). As we have seen, Young, Wilco, and U2 - all surely participating in the "postmodern" in their mutual flattening out of history and persistent appropriation of the styles of the Seventies-offer nostalgic texts that have everything to do with memory and desire.

The Tragically Hip likewise negotiate aspace that Hutcheon does not recognize, mining the division between infinity and "quick access" to quite different 
ends with "Fireworks," the third single from their 1998 album Phantom Power. The Hip, a Kingston-based quintet long celebrated across Canada, found a wider U.S. audience with Phantom Power and with a subsequent main-stage performance at the present-looking nostalgia-fest that was Woodstock 99. In the case of "Fireworks" we find the Hip resisting the logic of Canadian nationalism that had long sustained and enclosed the band (one could never go to a Hip concert without encountering Molson-drinking, flag-waving patriots in throwback Bill Barilko jerseys). "Fireworks" employs present-looking Seventies nostalgia in a bold effort to challenge their Canadian fans, gain new fans internationally, and situate themselves in the narrow intersection between love, hockey, and national identity.

The song also employs present-looking Seventies nostalgia as a means of critiquing the wider phenomenon of national-mythology-couched-in-Seventiesnostalgia. In this sense, "Fireworks" inhabits Davis's third order of nostalgia, interrogating and rendering problematic the nostalgic process itself (24). To enact their sociology of nostalgia, however, the Hip posit the Seventies as a heroic journey toward a self-aware and rebellious identity in love; thus the band's critique of mainstream nostalgia is itself leveled in nostalgic terms. In idealizing the Seventies as a simpler time when nostalgia nevertheless came under critique, "Fireworks" inhabits the third and first orders of nostalgia simultaneously.

"Fireworks" opens with Paul Henderson's goal against the Soviets in the 1972 Summit series, identifying it as a moment of national solidarity: "If there's a goal that everyone remembers, / It was back in ol' 72 / We all squeezed the stick and we all pulled the trigger / And all I remember is sitting beside you." Already this scene seems uncanny. The speaker, witnessing one of the most memorable moments in the history Canadian sports, insists that "sitting beside you" is all that he can remember; despite his claims to limited memory, however, the speaker capably describes the goal for us. This contradiction becomes more understandable, however, when we realize that the speaker cannot distinguish the erotic possibility from the sporting event. Henderson's goal, Canadian identity as such, and the speaker's falling in love are called into being at exactly the same moment in 1972. Despite their simultaneity and interrelation, however, these events are not mutually fulfilling in that resistance to national mythologies becomes the premise of the newlyformed personal relationship: "You said you didn't give a fuck about hockey / And I never saw someone say that before .... You were loosening my grip on Bobby Orr." To express such indifference in this most sanctified of national moments would be scandalous. The verse even recoils in surprise at its own subversion ("I never saw someone say that before") and resigns itself to life on the outskirts of the nationalist norm ("we walked home the long way"). The goal marks the precise moment wherein the speaker is interpellated by nationalist myths and becomes excluded from them as well. The speaker is substituting erotic objects for each other, from Bobby Orr to the nation to "you," just as all three are called into being as partial objects of the drive simultaneously. The speaker's desire for the nation is desublimated into the desire for hockey heroes and further desublimated into an erotic and romantic encounter, all with one wrist shot and a simultaneous performative utterance. The song, then, offers a process of transition-a necessarily narrative 
event-paradoxically collapsed into a single instant: it makes radical the very ahistorical flattening that Jameson finds unsatisfactory in nostalgia. The narrative steps out of proper time and proceeds on the level of the drive. Desire, it seems, is once again central to an understanding of present-looking Seventies nostalgia. "Fireworks" is a song that directly examines both memory and desire, straightforwardly resisting Hutcheon's claim about the postmodern nostalgic mode.

Despite the lovers' refusal of patriotic expectations in "Fireworks," the success of their resistance nevertheless depends upon maintaining equally restrictive notions of the couple: "We hung out together every single moment / "Cause that's what we thought married people do." Their love for each other, then, comes to replace and resist the (seemingly more conventional) love of politicized hockey, superimposing and intertwining personal and political spaces. The twin crises offered in the phrase "crisis of faith and crisis in the Kremlin" should thus be understood as neatly parallel and equivalent in the context of the song. In this sense, "Fireworks" substantiates Davis's claim that nostalgia can jeopardize the distinction between public and private (vii). Even so, the lovers continue to define their own identities in resistance to the culture at large: "Isn't it amazing what you can accomplish / When you don't let the nation get in your way," singer and lyricist Gordon Downie marvels, noting that the lovers' achievement is especially amazing when juxtaposed against "comrades in the National Fitness Program / Caught in some eternal flexed-arm hang." Despite the heroism of their resistance to nationalism and the nostalgic recollection of this resistance, however, the song more accurately might be said to offer an account of a simple substitution: the lovers merely replace Canada with "the country of me and you" as an object of their nationalism and nostalgia.

If, for the Hip, the Seventies become a moment of enlightenment that emerges against a wave of nationalism, the late Nineties become the time to muse nostalgically on this miniature revolution. From his late-Nineties vantage point, Downie describes the Seventies as a golden age of innocence, discovery, and naïveté that, although it has since crumbled, loosed an immutable marriage and Henderson's "timeless" goal upon the world. Downie's double perspective as he speaks from 1972 and 1998 simultaneously qualifies the song as a good example of presentlooking Seventies nostalgia. The song's chorus comes out against impermanence: the "temporary towers" of fireworks become the real villains of this song despite their beauty, menacing and obscuring the more durable and authentic stars. But the permanence implied by the speaker's love and nostalgic reflection resists the chorus's star/firework distinction. If the marriage spawned in the moment of Henderson's goal really is the "one thing [that] probably never goes away," would it not share its structure of permanence with national myths? Why would the myth of the indissoluble heterosexual couple be preferable to sporting or political myths? Wouldn't Henderson's goal be more a star than a firework in the "approved" national imagination, as evidenced by the fact that Downie is singing about it twenty-six years later?

Downie's brand of nostalgia, however subversive, does not seem to allow for an awareness of change, of temporality. It is not the kind of historical understand- 
ing that Jameson recommends as the antidote to the nostalgic mode. In this sense, Downie's nostalgia for the Seventies ultimately upholds the myths that the song claims to be challenging, even if it posits the decade as a window for cultural resistance. Thus the Hip appease their most nationalistic fans merely by alluding to this high point of Seventies nationalism, even while trying to resist the nationalist symbolism into which they themselves have become incorporated. Corroborating Philip Drake's claim that "[n]ostalgia . . . may be used to characterize a number of quite different and even contradictory impulses" (250), nostalgia in this case equips the Tragically Hip with the means of cultivating a form of national mythology even as they claim to defy it. This sort of ambivalence about a returning object marks "Fireworks" as an uncanny text. Far from simply collapsing the Seventies into the Nineties, the song resists chronological time by replacing a temporal narrative with a tale of desublimation that can still structure the song conventionally in lieu of conventionally understood chronology. By presenting the emergence of politics and the simultaneous emergence of countercultural erotics, and by tracking the story of the desublimation of Canadian politics across the Seventies and Nineties, the Hip offer present-looking nostalgia that refuses to give up on its desire even while remaining politically subversive.

Cornershop finds a different way to infuse present-looking Seventies nostalgia with political commitment. The band's album When I was Born for the $7^{\text {th }}$ Time became a worldwide hit in 1997 on the strength of the densely allusive single "Brimful of Asha." As if heralding its own effects, the album also featured the retroSeventies celebration "Funky Days Are Back Again." "Funky Days" drips with irony but is nevertheless genuinely welcoming to retro as a cultural phenomenon. The song holds especial interest for this study because, unlike "Fireworks," "I've Got You," or "Discotheque," it celebrates the late-Nineties return of Seventies culture more than it celebrates Seventies culture per se. As might seem inevitable in such cases, however, fondness for Seventies retro indirectly celebrates the original "funky days," just as the song's title fondly recalls Led Zeppelin's declaration that "dancing days are here again." The song, written and sung by Tjinder Singh, offers us a dark but optimistic vision of the Seventies' return. Singh joyously anticipates the lifestyle of hedonism, aesthetic of sass, and novelty of unabashed consumerism but equally accepts the attendant threats of labor disruption and new taxation schemes. Singh's repetitive lyrics might seem insipid at first-a nod to the coded banality of many disco lyrics - but both musically and lyrically the song proves subtler than it may at first seem.

"Once again, the name of the game is funky and it's funky again," proclaims Singh, firmly aligning his band with the triumphant side of the funky: "Funky funky days they're back again / And we're in vogue again." Still, this new era of undeniable funkiness has a limited tenure, as Cornershop acknowledges that they will only be in vogue until "the gurkers get called up again." In the face of such immanent military repression, Singh wittily insists on spelling "Funky with a " $y$ ", despite his reminder that "the party's got a double 'e' on the end again." Cornershop gauge the funkiness of their environment by evaluating its unique fashion sense and its ethic of novelty and consumption, ideologies that necessarily involve those 
workers who make funky products even while they consume them. Far from purveying "a quick fix and sugar-coated palliatives," as Boym has suggested of nostalgia's function in popular culture, Cornershop insists that capitalist redeployments of nostalgia carry political and economic consequences. Suggesting the political turmoil inherent and barely latent in consumer retro culture, Singh presents "the funky days" through a startling chain of equivalents: "Funky roads are back again / Funky drinks are back again / Zip-zap guns are back again / Big shoes are back again / Tax in the post is back again / Worker strikes are back again." The song continues on this ironic trajectory through to its conclusion, where Singh insists that his bandmate demonstrate Cornershop's funkiness: "Ben, you just show them how funky it can get when funky days are back in vogue again." Ben Ayers proceeds to hit a monotone on a cheap Casio and the song fades out immediately, forcing us to realize that the band's claim to funkiness will be limited and fleeting. In Freud's terms, the funky, once "having been an assurance of immortality . . . becomes the uncanny harbinger of death" to the movement (235). Cornershop offers a tribute to the return of funky days, but also recognizes how fleeting, tenuous, and politically volatile retro-Seventies funkiness proves to be. By including their own "fade out" as a demonstration of "how funky it can get" in the late Nineties, they recognize their own roles as heralds of the present-looking Seventies nostalgia and manage to place the entire phenomenon within a politicized historical context. Far from simply redeploying Seventies nostalgia to sustain an ahistorical pastiche, Cornershop roots their homage to funkiness in the ambivalent effects of a repetition: they savor precisely as uncanny the Seventies nostalgia of the late Nineties.

As if hosting an afterparty to Cornershop's ambivalent revelry, Beck delivered the most intelligent party record of 1999 with Midnite Vultures. On this record, Beck upholds both social and production values closely associated with the Seventies to the extent that reviewers went out of their way to insist that the record was not "merely" a Seventies tribute. Jon Pareles wrote that "[f]or all Beck lifts from the Seventies, the album never sounds like a period piece" in that Beck "doesn't set out to re-create the 1970s." Sean Flinn reformulated this reading in specifically nostalgic terms, claiming that "Beck, too young to clearly remember the " 70 s and early ' 80 s, puts on some second-hand nostalgia here . . . . Sure, Midnite Vultures borrows heavily from the last 30 years of African-American musical innovation, but ultimately it longs for a sound that has, sadly, never existed." University media echoed these sentiments. For instance, Barry McGuire proclaimed that "Beck Hansen plays the ... sexy rock superstar of the '70s, crooning lyrics that would make any woman of that decade (and this one, for that matter) swoon and sweat." In light of such defenses and their apparent necessity, it becomes important to acknowledge that the album makes few direct allusions to Seventies culture, more consistently and pointedly making reference to Nineties politics (calling out Norman Schwarzkopf in "Hollywood Freaks") and corporate globalization (cordially inviting Debra's sister to "step into my Hyundai"). Despite the Nineties allusions, reviewers did not tend to conclude that Beck was presenting the late Nineties as a time of restructured sexualities, crises in consumer and capitalist culture, and flamboyant hedonism; they insisted instead that these values qualify Midnite Vultures as a Seven- 
ties throwback.

In a layering of timeframes reminiscent of Young's "Downtown," Beck repackages the Seventies, Eighties, and Nineties as a sexualized and commoditized dreamscape. Beck proves far more adventurous than Young, however, in making cultural categories as inseparable as temporal ones. For all of the album's irreverence, Beck isn't kidding when he claims to "mix business with leather." Sexuality and commodity are always intertwined here ("She's all right touching my body ... She's all right selling me watches" and "I'll be your mistress C.O.D."); commodity and political influence come together ("With the cold cola cans / You'll get the keys to the city for free"); sexuality, gendered identity, and repressive state apparatuses become interlocked ("I want to defy the logic of all sex laws . . . . Let me be your chaperone / To the halfway home / I'm a full grown man but I'm not afraid to cry"); sex and social status become affiliated ("Touch my ass if you're qualified"); social classes become intermingled ("Peaches and Cream / You make a garbage man scream / Such a dangerous dream" and "Milk and honey / Pouring down like money / Bring a poor boy to his knees"); the juxtaposition of social classes becomes the basis of a sexual persona posing as authentic ("Ghettos and grey Rivieras / This is the real me ladies"); and sexual tensions play out as political allegories ("She looks so Israeli / Nicotine and gravy ... . I don't wanna die tonight”). To a significant extent, then, Midnite Vultures offers itself as a description of a culture that depends on conflating across and within categories of social status, sexuality, gender, and capital. If such conflation has long been fundamental to American culture, as Beck seems to be suggesting, then distinguishing between the Seventies and late Nineties might seem unimportant. But Beck offers the listener more than a diagnosis of late capitalist America. In a Seventies-nostalgic setting marked by the camp aesthetic demanded by an absurdist culture, Beck presents an ethics of postmodern Seventies nostalgia in his implied insistence that he always acts in conformity with his desire. Thus, untraditional and logically impossible sexual possibilities abound. In the sexiest rock-n-roll falsetto since Prince, Beck endearingly declares that "I wanna get with you / Only you / And your sister"; equally brilliantly, he promises to "feed you fruit that don't exist" and "leave graffiti where you've never been kissed." Beck proves willing to raise to the level of the categorical the new possibilities of libidinal investment that emerge when the Seventies and Nineties intersect nostalgically. Accordingly, we get an album whose most concrete imagery is purely fantasmatic. It is Beck who shows us the centrality of desire in "the very real and very uneasy tension between postmodern irony and nostalgia today," to employ Hutcheon's phrase (191).

Although Beck might strike some listeners as an artist of the nostalgic mode rather than mood - this is undoubtedly an antihistorical pastiche that problematizes linear time-Midnite Vultures nevertheless salutes a time that Beck, born in 1970, would have been too young to fully appreciate for its hedonism and commodity/ sexual fetishism. Midnite Vultures, in "sincerely" idealizing and yearning for a pastiche, upholds the nostalgic mood with the mode. As Rachman points out about Wayne's World, "that this is hilarious, even self-deprecating, doesn't detract from its sincere endorsement of the music and the culture that attends it" (43). 
Beck, like Wayne and Garth with Alice Cooper, offers a tribute to his too-sincere appreciation for a disfigured version of the Seventies. For Midnite Vultures, as with Wayne's World, the audience has to provide the reality-testing. The point that the reviewers missed is that Beck doesn't locate "fruit that don't exist" in any past decade, but rather offers an account of his desire as a tribute to that nonexistent fruit (the objet $a$ ), which was in the Seventies more than the Seventies.

From Davis and Jameson to Boym and Grainge, many pages have been valuably devoted to establishing nostalgia as a close associate of the capitalist commodity. Even outside of the discourse of psychoanalysis, however, nostalgia theory will have to become more flexible and attentive if it wants to remain useful in interpreting ambivalent texts. As we have seen, relationships between popular nostalgia and capitalism can be remarkably unstable: the return of the Seventies in the late Nineties was invariably marked by ambivalence to the Seventies as a decade, as a style of commodification, and as a lost object. Thus we should be neither surprised nor disappointed when the Seventies emerge from the present-looking late Nineties as a disfigured and unrecoverable object. The desire implied in the lateNineties nostalgia follows the Lacanian pattern of "because inexplicably I love in you something more than you . . I mutilate you" (Seminar XI 268). Nor should nostalgia theory decry the nostalgic pop culture commodity as insincere simply because it flattens out history, fails to recover its lost object, or mutilates the lost object. If we want to understand the mechanics of nostalgia in popular culture, we will need to insist on models of understanding nostalgia that can account for the uncanniness of the return, the differences between "simple" and present-looking nostalgia, and the elusive nature of the partial object of desire. Music fans of the late Nineties were neither purchasing nor downloading a glimpse into the lost object that was the Seventies-as current nostalgia theory would have us believe-but rather they were dreaming of rediscovering in the Seventies an objet a that always exceeded the Seventies itself.

\section{Notes}

' The songs discussed in this essay share critical and commercial "success" as measured in music industry terms: all of the albums that sheltered these songs were released by major labels, certified at least gold by the RIAA, and garnered four-star reviews by the arbiter of mainstream taste that is Rolling Stone magazine. The one exception is The Tragically Hip. whose album Phantom Power was not reviewed by Rolling Stone but which nonetheless consistently garnered four-star reviews across Canadian media and the northern U.S.

${ }^{2}$ One reason why studies of rock music tend to be androcentric is the masculinist structure of the marketing of the genre; by examining the trend in rock music rather than pop, country, trip-hop, or R\&B, the field of commercially successful female artists diminishes significantly.

${ }^{3}$ The female rockers of the period who did cast their messages nostalgically often turned to the imagery of the Sixties-Madonna's "Beautiful Stranger," Lauryn Hill's "Doo Wop (That Thing)," and the Indigo Girls come to mind-while the "inauthenticity" implied by much of the Seventies imagery became the idiom of so many male musicians. Although their songs are not considered here at length, bona fide female members of the Seventies nostalgia movement in late-nineties rock music include D'Arcy of the Smashing Pumpkins 
(who may or may not have played bass on "1979" but had no hand in its composition) and Nina Persson of the Cardigans (Persson is not the band's principal songwriter; I consider the band nostalgic because of their neo-Blondie sound and Black Sabbath covers). Although undoubtedly nostalgic, neither "1979" nor any nostalgic song in the Cardigans' catalogue could be understood to be present-looking.

${ }^{4}$ As a brief review, I will remind the reader that the original nostalgia theorist, Johannes Hofer of Mulhouse, coined the term in his doctoral dissertation in 1688. Nostalgia, initially believed to be fatal, remained a firmly medical category into the twentieth century; it did, however, become desirable for the first time in the nineteenth century as it became entangled with the phenomenon of nationalism (Boym 11). In the Fifties, nostalgia ended its career as a geographically-rooted malady, becoming recast as a temporal mood of yearning (Ritivoi 29; Davis 4; Hutcheon). Closer to the specificities of this topic, Jean Starobinski offers a fascinating account of nostalgia's historical relationship with music through Wagner (92).

${ }^{5}$ Rock-n-roll outfit Brother Cane released "Mirror Ball” in 1998, although the song was both less interesting and less commercially successful than the other examples discussed here. Outside of the rock format, Everything But the Girl's 1996 song "Mirrorball" provides another example of Seventies nostalgia, although the song might better enunciate Davis's "first order" or "simple" nostalgia than present-looking Seventies nostalgia (16-20). Sarah McLachlan's 1999 live album Mirrorball, although arguably nostalgic about the trajectory of her career, does not deploy Seventies nostalgia.

${ }^{6}$ Grainge's hypothesis in the context of Young's "psychedelic dream" also recalls Lacan's remark, quoted above, that "nostalgia ... perhaps means no more, like every dream of a Golden Age or El Dorado, than that we are engaged in posing questions at the level of the instinct."

\section{Works Cited}

Beck. Midnite Vultures. Geffen, 1999.

Biskind, Peter. Easy Riders, Raging Bulls: How the Sex-Drugs-and-Rock 'N'Roll Generation Saved Hollywood. New York: Simon \& Schuster, 1999.

Boym, Svetlana. The Future of Nostalgia. New York: Basic Books, 2001.

Copjec, Joan. Read My Desire: Lacan against the Historicists. Cambridge, MA: MIT Press, 1995.

Cornershop. When I Was Born for the $7^{\text {th }}$ Time. Wiija, 1997.

Creed, Barbara. "From Here to Modernity: Feminism and Postmodernism." Screen 28.2 (1987): 47-67.

Davis, Fred. Yearning for Yesterday: A Sociology of Nostalgia. New York: Free Press, 1979.

Doane, Janice, and Devon Hodges. Nostalgia and Sexual Difference: The Resistance to Contemporary Feminism. New York: Methuen, 1987.

Drake, Philip. “"Mortgaged to Music': New Retro Movies in 1990s Hollywood Cinema." Memory and Popular Film. Ed. Paul Grainge. Manchester: Manchester University Press, 2003. 242-265.

Flinn, Sean. Rev. of Midnite Vultures by Beck. Choler Magazine 30 Nov. 1999 <http:// www.choler.com/reviews/beck_midnite.shtml>.

Freud, Sigmund. "The Uncanny." The Standard Edition of the Complete Psychological Works of Sigmund Freud. 24 vols. Trans. James Strachey. London: Hogarth Press, 1964. 17: 218-256.

Grainge, Paul. Monochrome Memories: Nostalgia and Style in Retro America. Westport: Praeger, 2002.

Hart, James G. “Toward a Phenomenology of Nostalgia.” Man and World 6.4 (1973): 397- 
420.

Hutcheon, Linda. "Irony, Nostalgia, and the Postmodern." Methods for the Study of Literature as Cultural Memory. Ed. Raymond Vervliet and Annemarie Estor. Atlanta: Rodopi, 2000. 189-207.

Jameson, Fredric. "Nostalgia for the Present." South Atlantic Quarterly 88.2 (1989): 517537.

-. Postmodernism, or, the Cultural Logic of Late Capitalism. Durham, NC: Duke University Press, 1991

Kammen, Michael. Mystic Chords of Memory. New York: Knopf, 1991.

Lacan, Jacques. Seminar VII: The Ethics of Psychoanalysis. Ed. Jacques-Alain Miller. Trans. Dennis Porter. New York: Norton, 1992.

-. Seminar XI: The Four Fundamental Concepts of Psychoanalysis. Ed. Jacques-Alain Miller. Trans. Alan Sheridan. New York: Norton, 1978.

McGuire, Barry. Rev. of Midnite Vultures by Beck. Arizona Daily Wildcat 24 Nov. 1999 $<$ http://wildcat.arizona.edu/papers/93/66/11_2_m.html>.

McRuer, Robert. "Gay Gatherings: Reimagining the Counterculture.” Imagine Nation: The American Counterculture of the 1960s and 1970s. Ed. Peter Braunstein and Michael William Doyle. New York: Routledge, 2002. 215-240.

Miller, Stephen Paul. The Seventies Now: Culture as Surveillance. Durham, NC: Duke University Press, 1999.

Pareles, Jon. Rev. of Midnite Vultures by Beck. Rolling Stone 23 Nov. 1999 $<w w w . r o l l i n g s t o n e . c o m / n e w s / s t o r y / / i d / 5920704 / b e c k ? p a g e i d=r s . A r t i s t A r t i c l e s \&$ pageregion=mainRegion $>$.

Rachman, Stephen. "The Wayne's Worlding of America: Performing the Seventies in the Nineties." The Seventies: The Age of Glitter in Popular Culture. Ed. Shelton Waldrep. New York: Routledge, 2000. 41-53.

Ritivoi, Andreea Deciu. Yesterday's Self: Nostalgia and the Immigrant Identity. Lanham, MD: Rowman and Littlefield, 2002.

Sayre, Nora. Sixties Going on Seventies. Rev. ed. New Brunswick, NJ: Rutgers University Press, 1996.

Signoret, Simone. Nostalgia Isn't What it Used to Be. New York: Harper \& Row, 1978.

Starobinski, Jean. "The Idea of Nostalgia." Trans. William S. Kemp. Diogenes 54 (1966): 81-103.

Torok, Maria. "The Illness of Mourning and the Fantasy of the Exquisite Corpse." The Shell and the Kernel: Renewals of Psychoanalysis. By Nicolas Abraham and Torok. Ed. and trans. Nicholas T. Rand. Vol. 1. Chicago: University of Chicago Press, 1994. 107-124.

The Tragically Hip. Phantom Power. Sire, 1998.

U2. Pop. Island, 1997.

Wilco. Being There. Reprise, 1996.

Young, Neil. Mirrorball. Reprise, 1995.

-. Tonight's the Night. Reprise, 1975. 